\title{
Assessing blue orchard bee (Osmia lignaria) propagation and pollination services in the presence of honey bees (Apis mellifera) in Utah tart cherries
}

\author{
Natalie K Boyle ${ }^{\text {Corresp., } 1}$, Theresa L Pitts-Singer ${ }^{1}$ \\ ${ }^{1}$ USDA ARS Pollinating Insects Research Unit, Logan, UT, United States \\ Corresponding Author: Natalie K Boyle \\ Email address: natalie.boyle@ars.usda.gov
}

Osmia lignaria is a commercially available, native solitary bee species recognized for its propensity to forage upon and pollinate tree fruit crops such as apple, almond and cherry. This study evaluated the implementation of $O$. lignaria co-pollination with honey bees in central Utah commercial tart cherry orchards during 2017 and 2018 bloom. Three paired 1.2ha sites were selected for evaluation of cherry fruit set and yield with and without managed $O$. lignaria releases alongside the standard honey bee hive stocking rate of 2.5 hives/ha. Osmia lignaria supplementation did not measurably increase cherry fruit set, fruit per limb cross-sectional area or fruit weight. The lack of differences in yield is likely a consequence of local saturation of pollinator services supplied by managed honey bees throughout experimental orchards, such that no additive benefit of managed $O$. lignaria releases were measurable. An increase in managed $O$. lignaria populations was achieved in 2017 but not 2018, possibly due to unknown changes to orchard management or environmental factors. While flying $O$. lignaria in Utah tart cherries may support sustainable in-field bee propagation, their subsequent impacts on tart cherry yield were not detected when paired with standard stocking densities of honey bees. 
1 Assessing blue orchard bee (Osmia lignara) propagation and pollination services in the 2 presence of honey bees (Apis mellifera) in Utah tart cherries

3

4

5

6

7

8

9

10

11

12

13

14

15

16

17

18

19

20

21

22

23

24

25

26

27

28

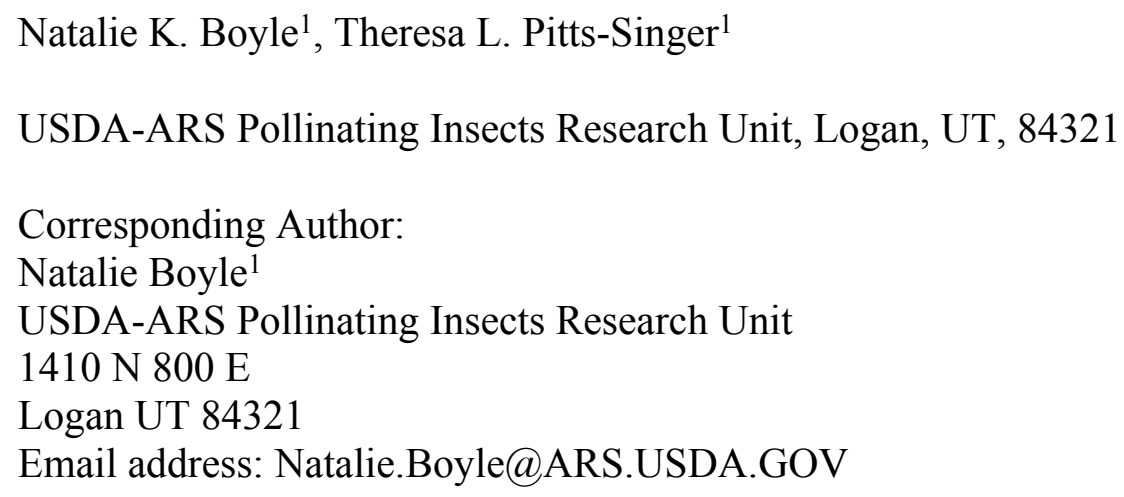

\begin{abstract}
Osmia lignaria is a commercially available, native solitary bee species recognized for its propensity to forage upon and pollinate tree fruit crops such as apple, almond and cherry. This study evaluated the implementation of $O$. lignaria co-pollination with honey bees in central Utah commercial tart cherry orchards during 2017 and 2018 bloom. Three paired 1.2ha sites were selected for evaluation of cherry fruit set and yield with and without managed $O$. lignaria releases alongside the standard honey bee hive stocking rate of 2.5 hives/ha. Osmia lignaria supplementation did not measurably increase cherry fruit set, fruit per limb cross-sectional area or fruit weight. The lack of differences in yield is likely a consequence of local saturation of pollinator services supplied by managed honey bees throughout experimental orchards, such that no additive benefit of managed $O$. lignaria releases were measurable. An increase in managed O. lignaria populations was achieved in 2017 but not 2018, possibly due to unknown changes to orchard management or environmental factors. While flying O. lignaria in Utah tart cherries may support sustainable in-field bee propagation, their subsequent impacts on tart cherry yield were not detected when paired with standard stocking densities of honey bees.
\end{abstract}

Keywords: Prunus cerasus, co-pollination, solitary bees, bee management 


\section{Introduction}

Fruit and nut tree crops comprise an important and critical segment of U.S. agricultural production, which relies heavily, and often exclusively, upon insect pollination to achieve profitable yields. Cherries are the eighth most valuable tree fruit crop, valued at nearly $\$ 950$ million in 2017 (Perez \& Minor 2018). With a 36\% increase in tart cherry yield projected for 2018 from the previous year (Perez \& Minor 2018), it is increasingly more important to consider the role and scope of insect pollination in the industry. As weather patterns during early spring blooms become less predictable, heavy rains and late frosts are expected to have measurable impacts on fruit yield (Cannell \& Smith 1986, Houston et al. 2018), in part because such inclement conditions do not support efficient honey bee foraging behavior. More than ever, growers may be able to benefit from the supporting wild and alternative managed insect pollinators to achieve the pollination requirements for profitable cherry production.

While tart cherries do not require insect pollination to set fruit, previous work has demonstrated up to five-fold increases in fruit set with insect-mediated cross-pollination (Shoemaker 1928, Free 1993). Most commercially available varieties are self-compatible, such that pollen transferred from an anther to the stigma of the same blossom can yield fruit. In the absence of insect pollination, tart cherry blossoms are reliant on wind and other abiotic factors for pollen transfer. Regardless, it is generally acknowledged that tart cherry orchards frequently benefit from added pollination services provided by insects, and as such, rented honey bee colonies are usually placed in tart cherry orchards during bloom.

The use of honey bees as commercially managed pollinators in monoculture is a standard choice that makes sense for growers, considering their ease of management, transport and their well-studied biology. However, given recent concerns over honey bee health and availability 
56 due to various known and potentially unknown risk factors (vanEngelsdorp et al. 2009), there is

57 now growing interest in supporting alternative wild and managed pollinators, whose

58 contributions to commercial agriculture have historically been overlooked (Garibaldi et al. 2013,

59 Isaacs et al. 2017).

The blue orchard bee, Osmia lignaria Say (Hymenoptera: Megachilidae), is among the

61

62

63

64

65

66

67

most widely studied native solitary bee species in the United States. Unlike honey bees, $O$.

lignaria have only one generation per year and are free-flying adults for just four to six weeks annually (Bosch \& Kemp 2001). Osmia lignaria are cavity-nesters and will reside gregariously in artificially-supplied hollow cavities such as reeds, corrugated wood blocks or cardboard tunnels (Bosch \& Kemp 2001). Females exhibit a foraging preference for rosaceous crops such as apples, almonds and cherries (Torchio 1979, Torchio 1985, Bosch \& Kemp 1999, 2001, Sheffield 2014), collecting pollen and nectar to construct provision masses for their offspring. Each egg is laid on top of its own provision, and the mother completes each cell by sealing it with a mud partition before the next provision mass is created (Bosch \& Kemp 2001). Under favorable conditions, one female can provision and lay eggs in over 15 cells in her lifetime (Bosch \& Kemp 2001). Osmia lignaria are spring-flying bees that forage in cooler temperatures than honey bees (Bosch \& Kemp 2001), making them well-suited for early-blooming and/or high elevation crops. The timing of their activity can be easily and actively manipulated through established cold storage incubation practices, such that they can be available to pollinate orchards any time between mid-February and late May. They also collect dry (unwetted) pollen underneath their abdomen (in coarse hairs that are collectively referred to as a 'scopa'), which facilitates pollen deposition and cross-pollination to flowers visited. Their anatomy and behavioron flowers yield more efficient pollination than for the honey bee, who stores wetted 
79

80

81

82

83

84

85

86

87

88

89

90

91

92

93

94

95

96

97

98

99

100

101

pollen in tightly-packed pollen baskets, or corbiculae (Parker et al. 2015). In fact, 275 female $O$. lignaria can provide pollination services comparable to a strong ( $>8$ frames) honey bee colony (Bosch \& Kemp, 2001). Finally, O. lignaria provide localized pollination services, as they do not typically forage beyond $100 \mathrm{~m}$ from their nest site (Bosch and Kemp, 2001), as long as local floral resources are abundant. In contrast, honey bees generally forage within $3.2 \mathrm{~km}$ of their hive (Eckert 1933) and have been observed foraging at distances upwards of $9.5 \mathrm{~km}$ (Beekman \& Ratnieks 2000).

Until recently, the biggest challenge for commercial-scale pollination by $O$. lignaria has been their limited supply. Growing public interest in wild and alternative bees over the past decade has led to the development of a competitive $O$. lignaria-based industry, from which the necessary quantities of bees are now available for field-scale trials and uses (Boyle \& PittsSinger 2017, Andrikopoulos \& Cane 2018, Pitts-Singer et al. 2018, Pinilla-Gallego \& Isaacs 2018). Recent studies have and continue to identify the crops and geographic regions in which managed $O$. lignaria populations best perform. Such examples include in California almond orchards, where co-pollination with a honey bees (at a full stocking density) with $O$. lignaria result in significantly improved fruit set and nut yield versus when either pollinator is used alone (Brittain et al., 2013; Pitts-Singer et al., 2018). We hypothesized that similar benefits of $O$. lignaria pollination in tart cherry orchards may be obtainable. The current study reports on the potential bee reproductive success and influence of $O$. lignaria co-pollination with honey bees on commercial tart cherry production in central Utah.

\section{Materials and Methods}

Experimental set-up and bee management. This trial was conducted over a contiguous 101ha swath of Montmorency cherries on Mahelab rootstock in Santaquin, UT during spring 
1022017 and 2018. Verbal permission to access and use the site was obtained via phone

103 conversations and meeting in person with the property (orchards) owner. All orchards were $10-$

10415 years in age and managed using the same general practices. Three square 1.2 ha plots $(110 \mathrm{x}$

$105110 \mathrm{~m}$; 'OL+') were selected to receive $O$. lignaria alongside honey bee hives (2.5 hives/ha). To

106 serve as a control, three paired 1.2 ha plots were additionally selected, where only honey bees

107 (2.5 hive/ha; 'OL-') were available for pollination (a randomized complete block design).

108 Experimental plots were separated by at least $100 \mathrm{~m}$ to minimize potential spillover effects of $O$.

109 lignaria foraging in controlled OL- plots (Fig. 1). Honey bee hives (2 deeps per hive) were

110 placed along orchard edges on pallets (four hives per pallet) to achieve the desired stocking

111 density; hives were owned and managed directly by contracted beekeepers.

112 Within the selected OL+ sites, eighteen nest boxes were uniformly distributed throughout

113 each 1.2 ha plot (5 boxes per row in 3 equally dispersed rows; Fig. 1). Nest boxes were made of

114 dark blue corrugated plastic boxes $(21.5 \times 20 \times 25.5 \mathrm{~cm})$, each housing one-hundred $7 \times 152 \mathrm{~mm}$

115 cardboard nesting tunnels lined with waxed paper straws. Each nest box was hung from tree

116 branches (ca. 1.2m above ground) with a southeast-facing entrance, in accordance with

117 established best management practices (Bosch \& Kemp 2001). Prior to their deployment, all

118 nest boxes were treated with a spray-on application of a patented chemical bee attractant (Pitts-

119 Singer et al. 2016) to promote bee nesting. No nesting accommodations were made for $O$.

120 lignaria in OL- orchard plots.

121 Osmia lignaria used in this study were acquired from a commercial supplier in Northern

122 Utah (both years); none of the 2017 progeny were allocated to the 2018 study. Bees were stocked

123 in OL+ orchard plots at a density of 625 females/ha, per the recommendation of Bosch \& Kemp

124 (2001). Bee release sites were located at the center of the three OL + plots where just-emerged 
125 adults and about-to-emerge adults in cocoons were placed in black fiberglass boxes ( $40 \times 25 \times 20$

$126 \mathrm{~cm}$ ), situated $\sim 12 \mathrm{~cm}$ above ground. Adult $O$. lignaria exited the release boxes naturally through

127 a small hole at the bottom of each box. For both years, approximately $40 \%$ of the bees had

128 emerged from their cocoons following an overnight 'preincubation' at room temperature prior to

129 orchard release. Bloom occurred on 29 April 2017 and 27 April 2018, and our corresponding $O$.

130 lignaria releases took place on 1 May 2017 and 30 April 2018, after the first 15\% of cherry

131 blossoms had opened and were receptive to pollination.

132 Osmia lignaria were left to mate and provision nests in the $\mathrm{OL}+$ treatments for four to

133 five weeks until just before the first scheduled post-bloom fungicide spray (however, O. lignaria

134 populations were exposed to a single nutritional spray during late May in 2017 and 2018). No

135 alternative floral resources were added for foraging adults in the orchards. While some wild

136 flowering weeds were present along orchard margins or between rows (e.g., dandelions), heavy

137 chemical control of orchard grounds greatly reduced the availability of non-cherry blossoms.

138 Details of spray timing and tank mixes were not shared with the authors of this study. All nest

139 boxes were returned to the laboratory, where nests were stored at room temperature while

140 offspring completed their development to adulthood. Individual Osmia lignaria nests were

141 examined using X-radiography frequently through late summer and early fall until all progeny

142 had become adults, at which time the bees were stripped from their paper tunnels, cleaned of

143 frass, loose pollen and pollen mites, and moved into cold storage $\left(4^{\circ} \mathrm{C}\right)$ as loose cocoons

144 throughout the late fall and winter months.Progeny recovered in 2017 weere released for various

145 other projects in orchards $>250 \mathrm{~km}$ from these experimental orchards.

146 Bee reproduction. All partial or fully completed $O$. lignaria nests were counted by nest

147 box and X-radiographed (6s exposure at $22 \mathrm{kVp}$; Faxitron 43804N, Faxitron Bioptics, Tuscon, 
148 AZ). From the X-radiographs, the total number of cells in each nest were counted and assessed 149 individually for survival, sex, parasitism and cause/stage of death where applicable (as described 150 in Boyle \& Pitts-Singer 2017 and Pitts-Singer et al. 2018). Wealso counted 'pollen balls', which 151 is when the provision mass remains uneaten due to the absence of an egg or the failure of that 152 egg to hatch in the cell. Due to differences by year in orchard plot site locations and climate, 153 inter-year statistical comparisons of $O$. lignaria progeny were not made. This decision was made 154 in part due to the 2018 removal and subsequent replanting of tart cherry acreage after the 2017 155 season. Annual differences in climate were evaluated by qualitatively comparing daily temperature and precipitation during and just following bloom, as provided by a neighboring weather station, located just $4.0 \mathrm{~km}$ SSE from our research plots (U. S. Climate Data).

Fruit production. To assess differences in 2017 and 2018 fruit set and yield between OL+ and OL- treatments, 20 trees from each 1.2 ha plot were randomly selected at bloom and assessed for percent fruit set, fruit weight and fruit per limb cross-sectional area (fruit/LCSA). One limb from each tree was marked and assessed for all three measurements, although the criteria for limb selection varied slightly between years. In 2017 , limb selection was confined to branches growing from the trunk of the tree and selected based on approximate length $(1-2 \mathrm{~m})$, aspect (SE-facing branch), and height above ground (1.3 - 2m). In 2018, limb selection criteria were modified so it would be possible to select a limb of a larger branch. Thus, limbs did not need to stem from the trunk of the tree. Other criteria in 2018 dictated limb length $(\sim 1 \mathrm{~m})$, age (third year growth), aspect (SE-facing branch) and height $(1.3-2 \mathrm{~m}$ above ground). At the proximal end of each selected limb, the limb circumference was measured $\left(\mathrm{cm}^{2}\right)$ to allow for fruit/limb cross-sectional area calculations. Because of the change to limb selection metrics between years, cross-year comparisons were not made. 
172 flowers occurring on selected limbs were counted and recorded during bloom. Then, just before

173 harvest (13 July 2017 and 16 July 2018), we returned to the same trees and counted how many

174 cherries had developed on selected limbs to calculate percent fruit set. The total number of

175 cherries on selected limbs were also incorporated into fruit per limb cross-sectional area

176 measurements. For fruit weight, 20 cherries from each randomly selected tree/limb were

177 collected and weighed as pooled samples in the laboratory. Differences in OL+ and OL- fruit

178 set, fruit/LCSA and weight were statistically analyzed separately by year in a randomized

179 complete block design via two-way ANOVA in JMP (SAS Institute, 2015; main effects being

180 OL+/OL-, or 'bees', and plot).

\section{Results}

Bee reproduction. The production of bee progeny varied by year. Cell outcome and

additional summary data (cells produced, cells/tunnel and sex ratio) are presented in Table 1 . In 2017, more viable female progeny had been recovered than were released into the orchard (111\% female recovery). In contrast, 2018 female recovery was much lower (32\%). The proportion of recovered cells containing viable offspring also differed across years: In $2017,90 \%$ of all cells recovered contained viable progeny, while just $75 \%$ of recovered 2018 cells were viable. Some of the 2018 loss in progeny may be attributable to an increase in nests containing uninterrupted provision masses extending throughout the length of the nesting tunnel in the absence of any eggs, mud partitions, or mud plugs at the end of the tunnel (Fig. 2). In 2018, this runaway pollencollecting behavior was observed in $29 \%$ of all nesting tunnels (versus $<1 \%$ in 2017 ). There was also a relatively higher rate of progeny in 2018 that died during larval/pupal development, along with a proportionally higher incidence of individual pollen balls. Along with much lower overall 
194 recovery of bees in 2018, there were proportionally fewer viable females recovered relative to 195 males (see sex ratios in Table 1).

196 Climate data. Weather conditions during cherry bloom favored warmer overall

197 temperatures in 2018 (average daily high/low temperature during bloom: $21.3 / 7.4^{\circ} \mathrm{C}$ ) than in

1982017 (average daily high/low temperature during bloom: 19.7/5.9 ${ }^{\circ} \mathrm{C}$ ). Levels of precipitation

199 during bloom were similar (7.5 $\mathrm{cm}$ in 2017 versus $5.3 \mathrm{~cm}$ in 2018$)$, although most precipitation

200 received in 2017 came down in a single day as snow $(5.1 \mathrm{~cm})$, whereas 2018 precipitation came

201 down gradually as rain on nine different days. Additionally, during 2017 bloom, there were four

202 days in which freezing temperatures were recorded, while no freezes occurred in 2018.

Fruit production. Statistical analyses did not support our hypothesis that $O$. lignaria

204

205

206

207

208

would influence fruit set or yield in this study (Table 2). Fruit set and yield, by plot $( \pm$ SEM)

and year, are presented in Figure 3. Overall, the specific location of the paired OL+/OLexperimental plots within the orchard had a significant effect on fruit set and yield, while the implementation of O. lignaria did not (Table 2; Fig. 3). In 2018, fruit weight was significantly higher in OL- versus $\mathrm{OL}+$ treatments $(\mathrm{F}=4.73, P=0.0316)$; cherry weight increased by $2.8 \%$ when O. lignaria were not introduced.

\section{Discussion}

Our data demonstrated that $O$. lignaria pollination in this scenario had only a very limited, and not reproducible, impact on tart cherry pollination services (significantly heavier cherries were obtained from OL- plots versus OL+ plots in 2018). Previous work in almonds has demonstrated a functional pollination synergy when $O$. lignaria pollination is used in tandem with the traditional stocking density of honey bee hives ( 5 hives/ha; Brittain et al. 2013, PittsSinger et al. 2018). However, unlike with almonds, tart cherries are self-pollinating, such that 
217 insect pollination is not required for trees to bear fruit. Regardless, it is known that insect

218 pollination can significantly increase yields even in self-compatible cropping systems (Erickson

219 et al. 1978, Lansari \& Iezzoni 1990, Sabbahi et al. 2005), which is why honey bees are

220 frequently rented by tart cherry producers during bloom.

221

Fruit set measurements in 2017 and 2018 were typical for Montmorency cherries

222 (Shoemaker 1928), suggesting that pollination was not a limiting factor in any of the OL+ or OL-

223 plots evaluated in this study. The lack in consistent statistical differences between OL+ and OL-

224 plots imply that the employed stocking rate of managed honey bee colonies already maximize

225 the potential for high rates of fruit set. Shoemaker (1928) reports the fruit setting rate of

226 Montmorency trees to be approximately $6 \%$ in the absence of cross-pollination and $25-30 \%$

227 with hand- or insect-pollination. Thus, $25-30 \%$ fruit set is the maximum fruit set that can be

228 expected in the present study. Because 2017 and 2018 fruit set ranged from $22-30 \%$ there is no

229 doubt that insect-mediated pollination maximally benefitted tart cherry production. Ashman et

230 al. (2004) suggests that after a known pollinator density threshold is reached, the additive effect

231 of increasing pollinators in a given orchard does not improve yields at harvest. This is likely the

232 case in the current study, such that 2.5 honey bee hives/ha is sufficient in meeting pollination

233 demands of tart cherries without the addition of managed $O$. lignaria populations. Further, there

234 is a possibility that foraging $O$. lignaria may have traveled beyond the reported $100 \mathrm{~m}$ foraging

235 range, which may interfere with our interpretation of treatment groups. However, as central-

236 place foragers, we find it unlikely that foraging adults would regularly and preferentially access

237 blossoms that fall outside their typical flight range, especially considering the uniformity and

238 high abundance of resources in the local vicinity. From these results, we are not able to gauge the 
239 effectiveness of $O$. lignaria as cherry pollinators when no adjustments to honey bee stocking

240 density are made.

241 No net gain in cherry yield from the release of managed $O$. lignaria populations was

242 observed, and differences between years in fruit/LCSA as presented in Table 1 are merely a

243 consequence of the revision to limb selection criteria in 2018 . We found it interesting that the

244 specific location of paired OL+/OL- plots within experimental orchards provided more

245 substantial effects on yield than pollinator inputs, highlighting that even within a relatively

246 uniform geographic area, microclimatic conditions, or slight variations in irrigation or soil

247 profile, may significantly influence fruit yield. For example, Fruit/LCSA in 2017 and 2018 is

248 highest in the northernmost paired plots, although the trend does not carry over for

249 corresponding fruit weight and set metrics.

250

Regardless of the lack of significant differences detected, alternative pollination may still

251

252

253

254

255

256

257

258

259

260

261

serve as an appropriate 'pollinator insurance' against unplanned honey bee colony shortages or in conditions where adverse weather may not be conducive to honey bee foraging. Cooler and wetter days are known to have measurable impacts on fruit set potential (Choi \& Anderson 2001) along with decreased pollinator activity (Vincens \& Bosch 2000), and O. lignaria readily forage at cooler morning temperatures than honey bees do (Bosch \& Kemp 2001). 2017 was overall a cooler year than 2018, although this did not appear to yield any meaningful differences in the efficacy of fruit set and yield for this study. We propose that there would be value in conducting future studies which examine $O$. lignaria impacts on yield in orchards lacking, or with fewer honey bee hive stocking densities.

Sustainable O. lignaria reproduction was achieved in 2017 but not 2018, and the 2018 failure in bee success is probably tied to the runaway pollen-collecting behavior observed in 
262 many of the nesting tunnels that year. While we occasionally observe this behavior by $O$.

263 lignaria in nesting tunnels, the frequency at which we observed this runaway pollen-collecting in

2642018 was exceptional and somewhat alarming. The cause of this behavior is unknown but may

265 reflect the quality/condition of the bees that were released, environmental factors, pesticide use,

266 or changes to orchard management. Private $O$. lignaria pollination consultants with contracts in

267 neighboring orchards during 2018 did not observe this behavior (K. Clark, Pers. Comm.). It is

268 worth noting that the seemingly abnormal behavior of some bees still resulted in active

269 contributions to cross-pollination of cherry blossoms during bloom, despite the limited progeny

270 recovered in 2018.

The ability to achieve sustainable and reliable in-orchard bee return is a known challenge

272 to the management of this bee. Today's supply of $O$. lignaria is met by collecting cocoons from

273 native populations in trap nests placed in wildlands across the Western U.S. (Tepedino \&

274 Nielson 2017). This practice escalates environmental and financial costs associated with

275 employing O. lignaria as alternative pollinators. Historically, bee return year-after -year can

276 vary substantially, with typical returns in commercial almond orchards with a full honey bee

277 stocking density ranging 30 - 40\% (Artz et al. 2013, 2014; Pitts-Singer et al. 2018). Boyle \&

278 Pitts-Singer (2017) observed a 2-fold increase in bee reproduction in a 2016 Utah tart cherry

279 orchard, and in 2017, 1.1x more progeny was recovered at the end of bloom than bees were

280 released. We propose that, despite the low reproduction obtained in 2018, tart cherry orchards

281 may serve as an appropriate avenue for future open field, managed $O$. lignaria propagation

282 efforts, while also providing local pollination services to growers. Future studies are needed to

283 determine if $O$. lignaria can be used as supplements or replacements for honey bees when there

284 is a need or grower decision to employ fewer honey bee hives for crop pollination. 


\section{Acknowledgements}

286 We thank lab technicians Ellen Klomps and Craig Huntzinger, along with lab assistants Hannah

287 Jarvis, Penina Meatoga, Jenna Hanson, Alex Foster, and Emily Slingerland for assisting with set-

288 up and installation of field materials, collection of bloom data, and X-ray diagnoses of $O$.

289 lignaria nests. We also thank Utah State University students Andi Kopit, Morgan Dunn and Alan

290 Anderson for their help in experimental set-up and data collection in the orchards.

291 


\section{References}

293 Ashman T-L, Knight TM, Steets JA, Amarasekare P, Burd M, Campbell DR, Dudash MR, 294 Johnston MO, Mazer SJ, Mitchell RJ, Morgan MT, Wilson WG. 2004. Pollen limitation of plant reproduction: Ecological and evolutionary causes and consequences. Ecology, 85: $2408-2421$.

297 298

Andrikopoulos CP, Cane JH. 2018. Comparative pollination efficacies of five bee species on raspberry. Journal of Economic Entomology, 111: 2513 - 2519.

Beekman M, Ratnieks FLW. 2000. Long-range foraging by the honey bee, Apis mellifera L. Functional Ecology, 14: 490 - 496.

Bosch J, Kemp WP. 1999. Exceptional cherry production in an orchard pollinated with blue orchard bees. Bee World 80: $163-173$.

Bosch J, Kemp WP. 2001. How to Manage the Blue Orchard Bee as an Orchard Pollinator. Sustainable Agricultural Network, Handbook No. 5, Beltsville, MD.

Boyle NK, Pitts-Singer TL. 2017. The effect of nest box distribution on sustainable propagation of Osmia lignaria (Hymenoptera: Megachilidae) in commercial tart cherry orchards. Journal of Insect Science, 17: 1 - 5.

Brittain C, Williams NM, Kremen C, Klein A-M. 2013. Synergistic effects of non-Apis and honey bees for pollination services. Proceedings of the Royal Society B: Biological Sciences, 280: 20122767.

Cannell MGR, Smith RI. 1986. Climatic warming, spring budburst and frost damage on trees. Journal of Applied Ecology, 23: 177 - 191. 
313 Choi C, Anderson RL. 2001. Variable fruit set in self-fertile sweet cherry. Canadian Journal of $314 \quad$ Plant Science, 81: $753-760$.

315 Eckert JE. The flight range of the honeybee. Journal of Agricultural Research, 47: $257-285$.

316 Erickson EH, Berger GA, Shannon JG, Robins JM. 1978. Honey bee pollination increases

317 soybean yields in the Mississippi delta region of Arkansas and Missouri. Journal of $318 \quad$ Economic Entomology, 71: $601-603$.

319 Free JB. 1993. Insect pollination of crops. San Diego: Academic Press Inc.

320. Garibaldi LA, Steffan-Dewenter I, Winfree R, Aizen MA, Bommarco R, Cunningham SA, 321 Kremen C, Carvalheiro LG, Harder LD, Afik O, Bartomeus I, Benjamin F, Boreux V, Cariveau 322 D, Chacoff NP, Dudenhöffer JH, Freitas BM, Ghazoul J, Greenleaf S, Hipólito J, Holzschuh A, 323 Howlett B, Isaacs R, Javorek SK, Kennedy CM, Kerwenka KM, Krishnan S, Mandelik Y, 324 Mayfield MM, Motzke I, Munyuli T, Nault BA, Otieno M, Peterson J, Pisanty G, Potts SG, 325 Rader R, Ricketts TH, Rundlöf M, Seymour CL, Schüepp C, Szentgyörgyi H, Taki H, 326 Tscharntke T, Vergara CH, Viana BF, Wagner TC, Westphal C, Williams NM, Klein A-M. 327 2013. Wild pollinators enhance fruit set of crops regardless of honey bee abundance. Science, 328 6127: $1608-1611$

Houston L, Capalbo S, Seavert C, Dalton M, Bryla D, Sagili R. Specialty fruit production in the Pacific northwest: adaptation strategies for a changing climate. Climatic Change, 146: 159 $-171$.

Isaacs R, Williams NM, Ellis J, Pitts-Singer TL, Bommarco R, Vaughn M. 2017. Integrated crop pollination: Combining strategies to ensure stable and sustainable yields of pollinationdependent crops. Basic and Applied Ecology, 22: $44-60$ 
335 Lansari A, Iezzoni A. 1990. A preliminary analysis of self-incompatibility in sour cherry.

336

337

338

339

340

341

342

343

344

345

346

347

348

349

350

351

352

353

354

355 Horticultural Science, 25: 1636 - 1638.

Parker AJ, Tran JL, Ison JL, Bai JDK, Weis AE, Thomson JD. Pollen packing affects the function of pollen on corbiculate bees but not non-corbiculate bees. Arthropod-Plant Interactions, 9: $197-203$.

Perez A, Minor T. 2018. Fruit and tree nuts outlook. 2018. United States Department of Agriculture Economic Research Service Situation and Outlook Report. FTS-367. Available at https://www.ers.usda.gov/webdocs/publications/90239/fts-367.pdf?v=1563.4 (accessed 7 February 2019).

Pinilla-Gallego MS, Isaacs R. 2018. Pollen use by O. lignaria (Hymenoptera: Megachilidae) in highbush blueberry fields. Annals of the Entomological Society of America, 111: 335 - 340

Pitts-Singer TL, Kemp WP, Moreland D, Peterson S, Buckner JS, Hagen M. 2016. U.S. Patent No. US 9,301,501 B2. Bee Attractants.

Pitts-Singer TL, Artz DL, Peterson SS, Boyle NK, Wardell GI. 2018. Examination of a managed pollinator strategy for almond production using Apis mellifera (Hymenoptera: Apidae) and Osmia lignaria (Hymenoptera: Megachilidae). Environmental Entomology, 47:364 - 377.

Rust RW. 1974. The systematics and biology of the genus Osmia, subgenera Osmia, Chalcosmia, and Cephalosmia (Hymenoptera: Megachilidae). The Wasmann Journal of Biology, 32: $1-93$.

Rust RW. 1990. Spatial and temporal heterogeneity of pollen foraging in Osmia lignaria propinqua (Hymenoptera: Megachilidae). Environmental Entomology, 19: 332-338. 
356 Sabbahi R, DeOliveira D, Marceau J. 2005. Influence of honey bee (Hymenoptera: Apidae)

357 density on the production of canola (Crucifera: Brassicacae). Journal of Economic Entomology, $35898: 367-372$.

359 SAS Institute. 2015. JMP ${ }^{\circledR}$, Version 12. SAS Institute, Cary, NC, USA.

360 Sheffield CS. 2014. Pollination, seed set and fruit quality in apple: studies with Osmia lignaria

361 (Hymenoptera: Megachilidae) in the Annapolis Valley, Nova Scotia, Canada. Journal of

362 Pollination Ecology, 12: 120-128.

363 Shoemaker JS. 1928. Cherry pollination studies. Extension Bulletin 422, Ohio Agricultural

364 Experiment Station, Wooster, Ohio.

365 Tepedino VJ, Nielson D. 2017. Bee-rustling on the range: Trap-nesting for pollinators on public 366 lands. Natural Areas Journal, 37, 265-269.

367 Torchio PF, 1979. Use of Osmia lignaria Say as a pollinator of caged almond in California.

368 Proceedings of the IVth International Symposium on Pollination, Maryland Agricultural

369 Experiment Station Miscellaneous Publication, 1: 285-293.

370 Torchio, PF, 1985. Field experiments with the pollinator species, Osmia lignaria propinqua

371 Cresson in apple orchards: V, (1979-1980), method of introducing bees, nesting success, seed

372 counts, fruit yields (Hymenoptera: Megachilidae). Journal of the Kansas Entomological Society,

373 58: 448-464.

374 U.S. Climate Data. Available at http://www.usclimatedata.com (accessed 11 February 2019).

375 vanEngelsdorp D, Evans JD, Saegerman C, Mullin C, Haubruge E, Nguyen BC, Frazier M,

376 Frazier J, Cox-Foster DL, Chen Y, Underwood R, Tarpy DR, Pettis JS. 2009. Colony

377 collapse disorder: a descriptive study. PLoS ONE 4: e6481. 
378 Vincens N, Bosch J. 2000. Weather-dependent pollinator activity in an apple orchard, with special reference to Osmia cornuta and Apis mellifera (Hymenoptera: Megachilidae and Apidae). Environmental Entomology, 29: 413 - 420. 


\section{Figure Captions}

Figure 1. Aerial map of three paired OL+/OL- locations selected for 2018. Each flag corresponds to the location of an artificial $O$. lignaria nest box (6 per row across 3 equally dispersed rows). Nest boxes were placed only in OL+ sites; empty white squares without flags correspond to OL- sites. Managed bee releases took place at the center of each OL+ site.

Figure 2. Example of a X-radiograph (June 2018) used to assess $O$. lignaria nest contents after recovery from the field. This image reveals the contents of 6 nesting tunnels. Tunnels 1, 2, 3, and 6 depict developing bees, where provisions, larvae, mud partitions and a mud plug at the terminus (tunnels 1-3 only; right side) of the nest are clearly visible. Tunnels 4 and 5 depict extended, singular provision masses in which no eggs, larvae, mud partitions or plugs are present. This unusual pollen-collecting behavior was observed in $29 \%$ of all nesting tunnels used in 2018 (versus $<1 \%$ in 2017).

Figure 3. Mean ( \pm SEM) values for each paired 1.2ha orchard site in 2017 (left half) and 2018 (right half) pollination trials comparing honey bee pollination versus honey bee and $O$. lignaria co-pollination in Utah tart cherries. Solid bars signify OL-, or A. mellifera only, while hashed bars signify $\mathrm{OL}^{+}$, or $A$. mellifera with $O$. lignaria sites for A) proportion fruit set, B) individual cherry weight and C) fruit per limb cross-sectional area (LCSA). Lower fruit/LCSA obtained in 2018 is a consequence of the adoption of new limb selection criteria only. 


\section{Table $\mathbf{1}$ (on next page)}

Table 1: Summary table of 2017 and 2018 O. lignaria nesting and progeny outcomes in a Utah tart cherry orchard.

Mean ( \pm SEM) per 1.2 ha plot is reported, followed by the percent progeny outcome in parentheses (where applicable). 
1 Table 1: Summary table of 2017 and $2018 O$. lignaria nesting and progeny outcomes in a 2 Utah tart cherry orchard. Mean ( \pm SEM) per 1.2 ha plot is reported, followed by the percent 3 progeny outcome in parentheses (where applicable).

\begin{tabular}{cll}
\hline Mean \pm SEM (\%) & $\mathbf{2 0 1 7}$ & $\mathbf{2 0 1 8}$ \\
\hline Tunnels filled (\%) & $38.4 \pm 5.7$ & $10.0 \pm 2.1$ \\
Cells Recovered & $220.1 \pm 40.2$ & $62.0 \pm 13.6$ \\
Cells/Tunnel & $5.1 \pm 0.13$ & $5.6 \pm 0.33$ \\
Sex Ratio (M:F) & 1.85 & 2.67 \\
Females & $69.5 \pm 13.1(30.5 \%)$ & $13.1 \pm 3.2(20.3 \%)$ \\
$\quad$ Males & $128.4 \pm 23.8(56.3 \%)$ & $35.1 \pm 7.8(54.3 \%)$ \\
Immature Dead $^{\text {a }}$ & $6.4 \pm 1.3(2.8 \%)$ & $8.3 \pm 2.0(12.8 \%)$ \\
Pollen Ball $^{\mathrm{b}}$ & $13.3 \pm 2.2(10.4 \%)$ & $8.0 \pm 1.7(12.4 \%)$ \\
Parasitized $_{\text {\% Female Return }}$ & $2.4 \pm 1.1(>1 \%)$ & $0.03 \pm 0.01(>1 \%)$ \\
\hline
\end{tabular}

4 ammature Dead includes all cells that failed to develop to become viable adults for unknown

5 reasons. This column pools larval, pupal and adult mortality, as confirmed by X-radiography.

6 bPollen ball occurs when the provision remains uneaten in the cell, likely due to egg failure. 


\section{Table 2 (on next page)}

Summary table of 2017 and 2018 tart cherry outcomes when 0 . lignaria were $(\mathrm{OL}+)$ and were not (OL-) introduced as co-pollinators with managed honey bee colonies at a rate of 2.5 hives/ha.

Mean ( \pm SEM) per 1.2 ha plot is reported with main effects statistics for each variable measured. Limb cross-sectional area (LCSA) was recorded are the proximal end of selected tree limbs, along the length of which developed fruit were counted to assess Fruit/LCSA. 
1 Table 2: Summary table of 2017 and 2018 tart cherry outcomes when $\boldsymbol{O}$. lignaria were 2 (OL+) and were not (OL-) introduced as co-pollinators with managed honey bee colonies at 3 a rate of 2.5 hives/ha. Mean ( \pm SEM) per 1.2 ha plot is reported with main effects statistics for 4 each variable measured. Limb cross-sectional area (LCSA) was recorded are the proximal end of 5 selected tree limbs, along the length of which developed fruit were counted to assess

6 Fruit/LCSA.

\begin{tabular}{rcclrr}
\hline & X OL- $( \pm$ SEM $)$ & X OL $+( \pm$ SEM $)$ & Variable & \multicolumn{1}{c}{ F } & \multicolumn{1}{c}{$P$} \\
\hline & & & Bees & 1.0611 & 0.305 \\
2017 Fruit Set $(\%)$ & $23.9 \pm 2.0$ & $22.2 \pm 2.0$ & Plot & 16.6798 & $<0.0001$ \\
& & & Bees & 0.0727 & 0.788 \\
2018 Fruit Set $(\%)$ & $30.3 \pm 1.9$ & $29.8 \pm 2.0$ & Plot & 2.328 & 0.1019 \\
& & & Bees & 0.3436 & 0.5588 \\
2017 Fruit/LCSA $\left(\mathrm{cm}^{2}\right)$ & $14.2 \pm 2.1$ & $15.9 \pm 1.0$ & Plot & 3.7403 & 0.0265 \\
& & & Bees & 1.0169 & 0.3153 \\
2018 Fruit/LCSA $\left(\mathrm{cm}^{2}\right)$ & $5.5 \pm 0.6$ & $6.2 \pm 1.0$ & Plot & 0.7724 & 0.4642 \\
& & & Bees & 0.98 & 0.3241 \\
2017 Fruit Wt $(\mathrm{g})$ & $4.0 \pm 0.1$ & $4.1 \pm 0.1$ & Plot & 5.3988 & 0.0057 \\
& & & Bees & 4.73 & 0.0316 \\
2018 Fruit Wt $(\mathrm{g})$ & $3.6 \pm 0.1$ & $3.5 \pm 0.1$ & Plot & 11.05 & $<0.0001$ \\
\hline
\end{tabular}




\section{Figure 1}

Aerial map of three paired OL+/OL- locations selected for 2018.

Each flag corresponds to the location of an artificial 0 . lignaria nest box ( 6 per row across 3 equally dispersed rows). Nest boxes were placed only in $\mathrm{OL}+$ sites; empty white squares without flags correspond to OL- sites. Managed bee releases took place at the center of each $\mathrm{OL}+$ site.

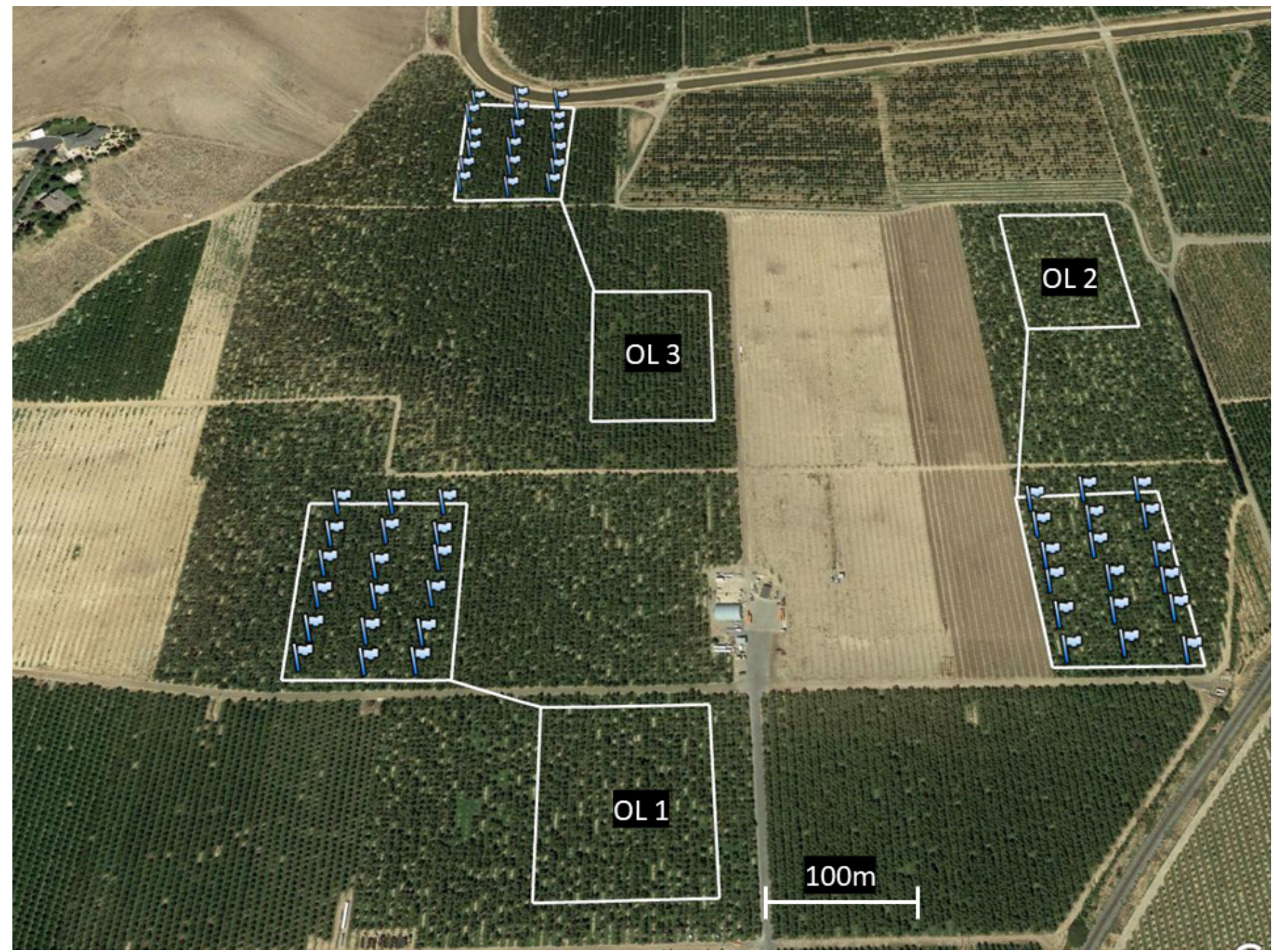




\section{Figure 2}

Figure 2: Example of a X-radiograph (June 2018) used to assess O. lignaria nest contents after recovery from the field.

This image reveals the contents of 6 nesting tunnels. Tunnels 1, 2, 3, and 6 depict developing bees, where provisions, larvae, mud partitions and a mud plug at the terminus (tunnels 1-3 only; right side) of the nest are clearly visible. Tunnels 4 and 5 depict extended, singular provision masses in which no eggs, larvae, mud partitions or plugs are present. This unusual pollen-collecting behavior was observed in $29 \%$ of all nesting tunnels used in 2018 (versus $<1 \%$ in 2017).

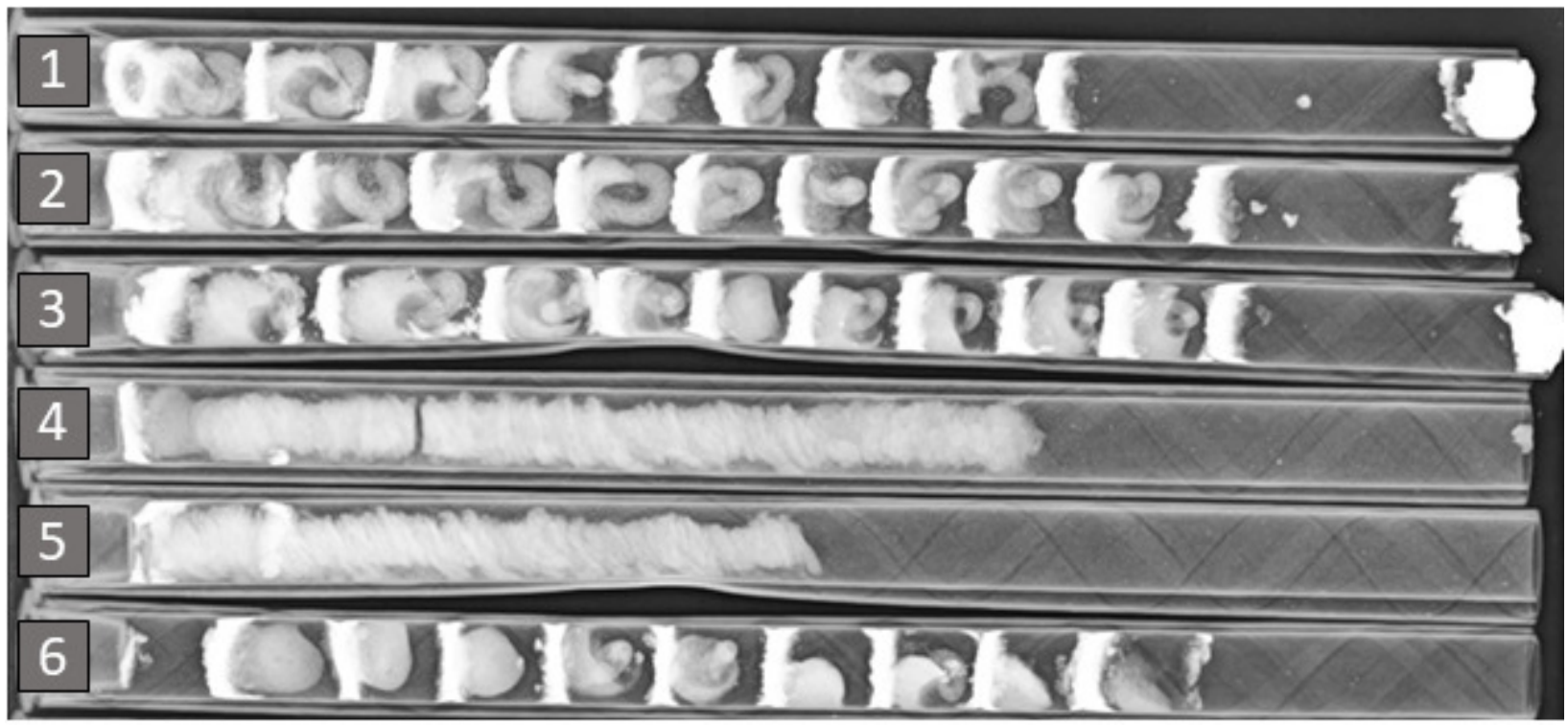




\section{Figure 3}

Mean ( \pm SEM) values for each paired 1.2ha orchard site in 2017 (left half) and 2018 (right half) pollination trials comparing honey bee pollination versus honey bee and 0 . lignaria co-pollination in Utah tart cherries.

Solid bars signify OL-, or $A$. mellifera only, while hashed bars signify $\mathrm{OL}+$, or $A$. mellifera with O. lignaria sites for A) proportion fruit set, B) individual cherry weight and C) fruit per limb cross-sectional area (LCSA). Lower fruit/LCSA obtained in 2018 is a consequence of the adoption of new limb selection criteria only. 

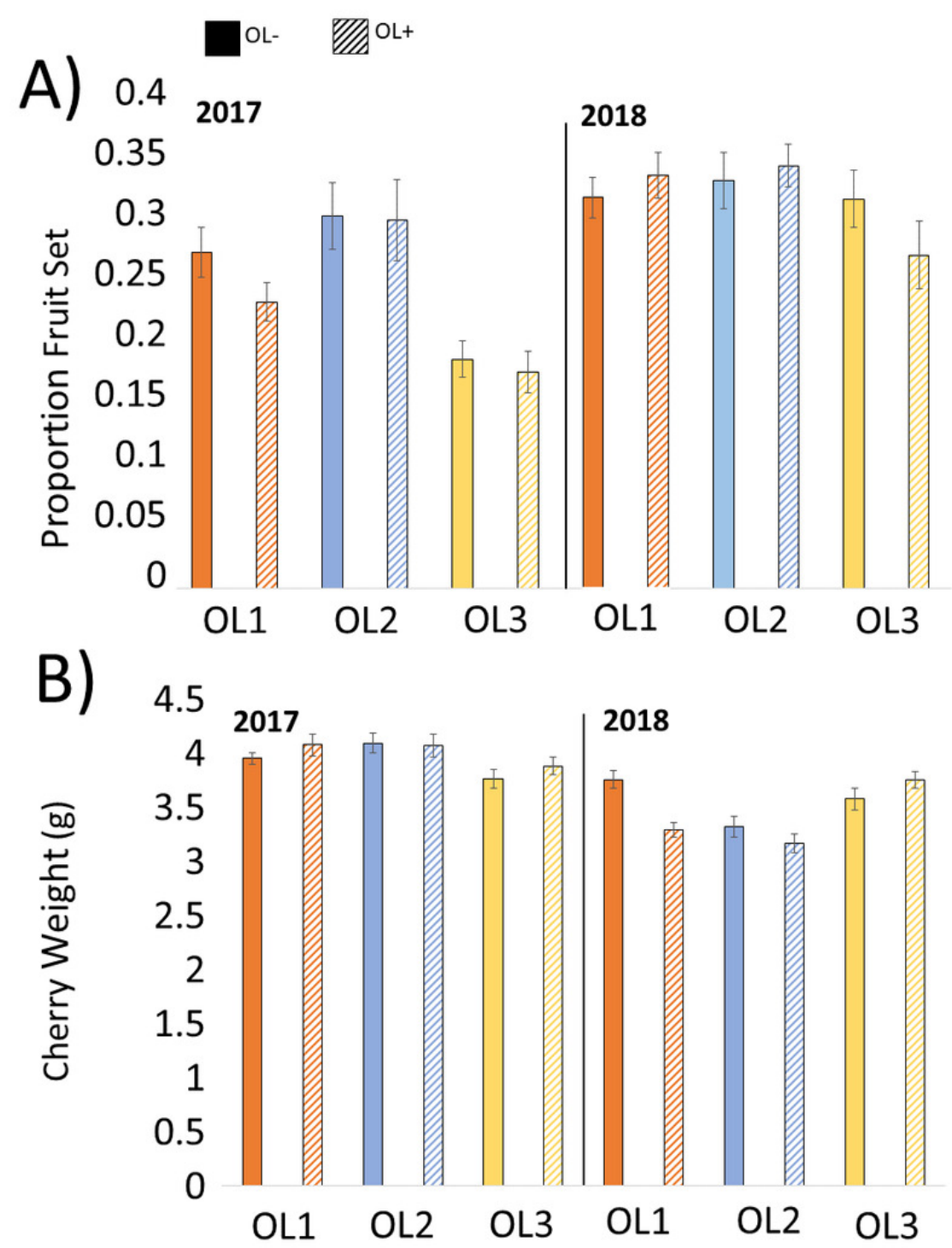

C) 0.25

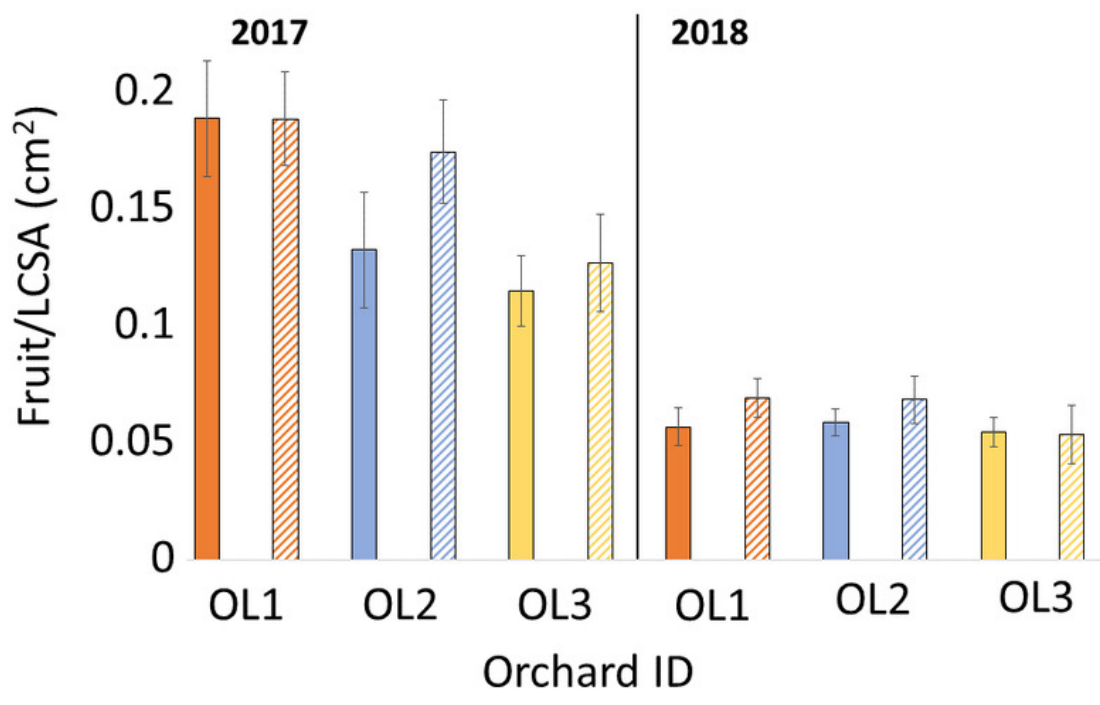

